\title{
Special Interest Section of a Core Mechanical Engineering Course - Bioma- terial Emphasis of an Introduction to Materials Course
}

\section{Dr. Margaret Pinnell, University of Dayton}

Dr. Margaret Pinnell is the Associate Dean for Faculty and Staff Development in the school of engineering and associate professor in the Department of Mechanical and Aerospace Engineering at the University of Dayton. She teaches undergraduate and graduate materials related courses including Introduction to Materials, Materials Laboratory, Engineering Innovation, Biomaterials and Engineering Design and Appropriate Technology (ETHOS). She was director of the (Engineers in Technical Humanitarian Opportunities of Service-Learning) for approximately ten years. She has incorporated service-learning projects into her classes and laboratories since she started teaching in 2000. Her research interests include community engaged learning and pedagogy, K-12 outreach, biomaterials and materials testing and analysis. 


\title{
Special Interest Section of a Core Mechanical Engineering Course - Biomaterial Emphasis of an Introduction to Materials Course
}

\begin{abstract}
The University of Dayton (UD) is part of the Kern Entrepreneurship Education Network (KEEN) which aims to instill the entrepreneurial mindset in engineering students through a collaboration among 24 colleges and universities across the US. To facilitate this, KEEN offers a variety of resources to individual engineering faculty as well as its network institutions. One such program offered by the University of Dayton is the KEEN Faculty Fellows Program. The objective of this program is to help engineering faculty understand innovative teaching strategies such as active and collaborative learning (ACL), project/problem based learning (PBL) and entrepreneurially minded learning (EML) and then use this information to modify a course or to create a new course. This paper will describe the modification of a core mechanical engineering course, Introduction to Materials, to have a Biomaterial focus, to employ ACL/PBL techniques and to include project based learning modules aimed at fostering the entrepreneurial mindset in the students. Because this is a core mechanical engineering course, the primary learning objectives for the Introduction to Materials course had to be met through this modified course offering. The efficacy of this modified course in comparison to the traditional Introduction to Materials course was assessed by comparing the final exam scores with those of a control group. Additionally, the students' perception of their learning was captured through student feedback forms facilitated at the conclusion of each of the projects as well as at the conclusion of the semester. Results from the assessments suggest that the modules did not negatively affect the overall learning of the students as measured by their performance on a common, cumulative final exam. Students generally liked the opportunity to apply their knowledge to real world problems that were thematically centered on the biomedical industry and to be able to work in teams.
\end{abstract}

\section{Introduction}

The Kern Entrepreneurship Education Network (KEEN) supported by the Kern Family Foundation was created in 2005 to "champion the entrepreneurial mindset in undergraduate engineering students." ${ }^{1-3}$ In an effort to achieve this goal, the Kern Family Foundation created a network made up of mostly private engineering schools that are committed to developing the entrepreneurial mindset in their undergraduate engineering students through the network schools' faculty and programs. Through KEEN support, engineering schools have had the opportunity to make investments in faculty, staff and students to transform engineering education with the ultimate goal of empowering the engineers of the future to create jobs and make the world a better place. ${ }^{2-6}$ This goal is captured in the mission of KEEN which is, "to graduate engineers 
with an entrepreneurial mindset so they can create personal, economic, and societal value through a lifetime of meaningful work."4

KEEN champions novel pedagogy in engineering such as Active Collaborative Learning (ACL), Project/Problem based Learning (PBL) and Entrepreneurial Minded Learning (EML). ACL and PBL are not new to engineering education, but EML is. ${ }^{2,3,7-10}$ EML is a student-centered pedagogy developed by KEEN that employs ACL/PBL with the goal of also developing the entrepreneurial mindset in the students. A key element of EML is to provide students with authentic learning experiences that make them better able to identify opportunities to create value in a product or process. ${ }^{2,3,11-12}$ EML supports the student's acquisition of both content knowledge and creative thinking strategies and skills and supports the intersection of engineering, business and societal needs. A cornerstone of EML is the synthesis of knowledge and experience from a variety of resources which makes it a high level of learning on the cognitive domain. ${ }^{13,14}$

The University of Dayton (UD) is one of 24 colleges that are part of KEEN. In 2014, UD received a $\$ 1.2$ million grant from KEEN to support the professional development of faculty and to create curriculum that would help engineering students develop curiosity, make connections and create value for their future employers as well as society at large. ${ }^{15}$ To facilitate this, UD created the KEEN Fellows program. The KEEN Fellows program at UD is a cohorted program, where faculty in engineering, mathematics, geology and other College of Arts and Sciences courses that have a large enrollment of engineering students can receive summer funding or course buy-out to develop curriculum, courses or innovative pedagogy that promotes the entrepreneurial mindset. The KEEN Fellows program includes training on ACL/PBL and EML as well as opportunities for faculty to exchange ideas and learn from one another. Curriculum developed through this program is shared with faculty from other schools in the network during KEEN meetings and will eventually be shared through an on-line platform. The first cohort of KEEN Fellows which commenced in January of 2015, was made up of 12 engineering faculty and three faculty from the College of Arts and Sciences. Faculty in this cohort engaged in a variety of activities including developing flipped classrooms, creating on-line learning, new course development and development of EML modules for existing classes. This paper will describe the modification of an existing required mechanical engineering course, Introduction to Materials Science (Materials), to have a thematic section focused on bioengineering applications.

\section{Thematic Material Science Course}

UD has realized tremendous growth in its Mechanical Engineering program over the past ten years. Currently, the department has approximately 800 undergraduate students representing about $10 \%$ of UD's total undergraduate student population. As a result, the department offers multiple sections of most of its required courses every semester. Although this has provided challenges with regards to staffing, it has also provided opportunities for faculty to create special sections of the courses that cater to the individual interests of the students. 
One particular interest of undergraduate mechanical engineering students is in the area of Bioengineering. Although UD does not offer a Bioengineering undergraduate degree, it does offer a Bioengineering Master's Degree. Undergraduate students can take some of the Bioengineering course offerings as technical electives and /or pursue a Bioengineering minor. Additionally, UD recently approved a Biomechanical Engineering minor. ${ }^{16}$ The field of Bioengineering is attractive to students for good reason. The US Bureau of Labor and Statistics estimates job growth in Bioengineering to be in excess of $23 \%$ over the next decade with a median annual salary of approximately $\$ 89 \mathrm{~K} .{ }^{17}$ Additionally, according to ASEE, the field of Bioengineering is highly attractive to females with approximately $40 \%$ of the undergraduates degrees in bioengineering being awarded to females which is the second highest of any specialty in engineering. ${ }^{18}$ In an effort to feed this interest, one section of an Introduction to Materials Science course was modified to have a Biomaterial focus, to employ ACL/PBL and EML techniques and to include project based learning modules aimed at fostering the entrepreneurial mindset in the students while also meeting course specific goals. Because this is a core mechanical engineering course, the primary learning objectives for the Introduction to Materials Science course had to be met through this modified course offering.

Introduction to Materials Science, MEE 312 (Materials) is a three semester hour, junior level course that is a requirement for the Bachelors of Mechanical Engineering degree at UD. This course covers basic material science topics such as chemical bonding, crystal structure, diffusion, mechanical testing and material properties, solidification, phase diagrams, heat treatment, metals and alloys, polymers, composites and ceramics. There is an accompanying one credit hour laboratory that covers primarily mechanical testing and material properties, data analysis and technical report writing and is fairly well aligned with the lecture portion of the course to provide reinforcing activities to the course content. Typically, UD offers three sections of Materials each semester and eight to ten sections of the lab. The course and lab are co-requisites, but occasionally a student will be in the class, but not the lab or be in the lab but not the class. This course usually has 30 to 40 students in each section of the class and 10 to 15 students in each section of the lab. Students in one section of the lab are not necessarily in the same section of class.

Through the KEEN Fellow program, one of the faculty members that teaches one to two sections of the lecture each semester and coordinates all of the laboratory sections with assistance from graduate student teaching assistants, modified one section of the lecture portion of the course to have a Biomaterial focus as described above. This faculty member had been teaching the materials course and associated laboratory for approximately 15 years prior to creating the thematic special section. During these 15 years, this faculty member had employed some ACL techniques in her classroom and typically assigned at least one project during the course of the semester. Additionally, she had created some EML modules for this course through another KEEN activity. ${ }^{19}$ This faculty member also had student evaluation scores that were consistently above the departmental average. 
The main objective associated with offering the special Biomaterial focus section of the Material course was to provide the students with a mechanism for making connections among the various chapters and units of the course and to promote student interest and engagement through the thematic inclusion of biomedical applications of materials. Additionally, it was hoped that the thematic focus would help to foster the entrepreneurial mindset of the students. Furthermore, as previously mentioned, since Materials is a required course, the objectives listed above had to be met without compromising the learning outcomes already established for the Materials course.

The Biomaterial focus section of the course was modified in several specific ways. One major change made to this section was the Course Schedule. The course schedule was adjusted to accommodate some additional topics that are not generally covered in the traditional Materials course, but were highly relevant to the Biomaterial focused section. Among these include Ethical and Legal Issues, Wound Healing, Corrosion Basics, Failure Analysis and Biomedical Applications of Materials as shown in Table 1. As a result of this, the laboratory activities did not match up as well with what was taught in the Biomaterial focused section as they did with the regular sections of Materials. Another change made to this Biomaterial focus section of materials was that the homework problems and projects assigned for this section of the course had a biomedical and Biomaterial emphasis. Examples of these are provided below in the Course Projects and Homework section. Other changes made to this section included the use of a flipped classroom format in the latter part of the semester. One thing that was not changed about this special section of the course was that ACL and PBL pedagogies were employed throughout the semester. As mentioned above, the faculty member that offered this special section of the course, had a long history of including ACL and PBL pedagogies in her course. As such, inclusion of these pedagogies was not new.

\section{Course Projects and Homework}

In the Biomaterial focused section of Materials specialized readings and other resources were posted on an on-leaning learning platform. No specific text book was used for this course. Students were assigned seven homework assignments worth ten points each, two mini-projects worth 25 points $(\sim 4 \%)$ each and two major projects worth 100 points ( 14\%) each. Additionally, there were four, five point $(>1 \%)$ quizzes over the flipped classroom lectures, two tests worth 100 points ( 14\%) each and a final that was worth 150 points (22\%) (690 total points). To promote community engagement, students had the opportunity to earn 20 points extra credit if they went to a K-12 classroom to facilitate an engineering design activity for the children. 
Table 1. Lecture Topics for Biomaterial Focused Section of Materials and Approximate Timing of Lab Activities/Topics.

\begin{tabular}{|l|l|}
\hline \multicolumn{1}{|c|}{ Lecture Topic } & \multicolumn{1}{c|}{ Lab Activity } \\
\hline Material Intro & \\
\hline Laboratory Overview & \\
\hline Atomic Structure & Safety and Tensile Testing \\
\hline Atomic Arrangment and Miller Indices & Tensile Data Anaysis \\
\hline Crystallographic Imperfections and Slip & Report 1 writing \\
\hline Diffusion & Strain Hardening \\
\hline Solidification and Phase Changes & Strain hardening Data Analysis \\
\hline Phase diagrams & Report 2 writing \\
\hline Cold Working and Annealing & Impact testing \\
\hline Age hardening & Report 3 writing \\
\hline Heat treatment of Steels & Heat treating (Age Hardening) \\
\hline Ethical and legal issues* & Heat treating of steels \\
\hline Wound healing* & Report 4 writing \\
\hline Corrosion basics* & \\
\hline Failure analysis* & \\
\hline Biomedical Applications of Materials* & \\
\hline Ceramics & \\
\hline Metals & Composite manufacture \\
\hline Polymers and Composites & Composite testing \\
\hline * indicates new topics added to Biomaterial Focused Section of Materials \\
\hline
\end{tabular}

Homework problems were developed to have a Biomaterial focus. For example, for a homework assignment that included concepts of the effect of atomic bonding on material properties, the students were given the following information related to materials that are used for Hip Implants:

Hip implants are a widely used biomedical application. These implants make use of a variety of different types of materials. To exemplify this point, see the figure provided below which shows hip implant constructions that make use of three distinct classes of materials (metals, polymers and ceramics). Properties of some common Biomaterials are also provided below in the table from Pillar (labeled as table 2.1) 


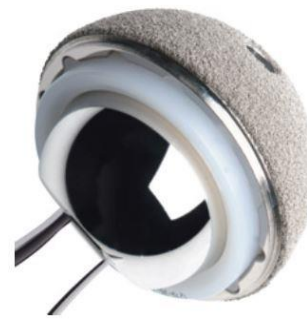

Metal on Polyethylene

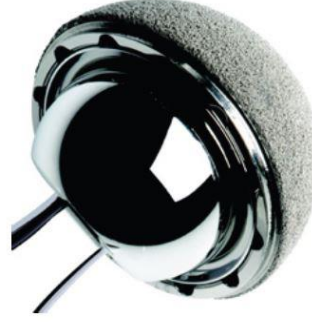

Metal on Metal

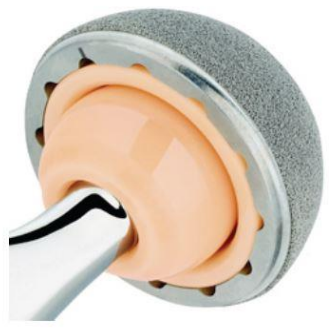

Ceramic on Ceramic

http://www.camdonfary.com.au/patientinfo/anteriorhipreplacement.html ${ }^{20}$

Table 2.1 Mechanical properties of metallic biomaterials. Small variations in E may be attributable to different measuring methods. The large range of strength and \% elongation to failure properties are due to different material processing. Some polymer and ceramic, as well as cortical bone properties are shown for comparison

\begin{tabular}{lllll}
\hline Material & E $(\mathrm{GPa})$ & $\sigma_{\text {yield }}(\mathrm{MPa})$ & $\sigma_{\text {ult }}(\mathrm{MPa})$ & $\%$ elong \\
\hline Fe-based & $200-205$ & $170-690$ & $540-1000$ & $12-40$ \\
Co-based & $220-230$ & $450-1500$ & $655-1900$ & $5-30$ \\
$\mathrm{CP} \mathrm{Ti}$ & $100-115$ & $170-480$ & $240-550$ & $15-24$ \\
$\mathrm{Ti}-$ based & $100-110$ & $585-1050$ & $690-1150$ & $10-15$ \\
$\mathrm{Ta}$ & 188 & $140-345$ & $205-480$ & $1-30$ \\
$\mathrm{Ni}-\mathrm{Ti}(\mathrm{Ms})$ & $28-41$ & $70-140$ & 895 & $\sim 9$ \\
$\mathrm{UHMWPE}$ & 0.5 & - & $\sim 3$ & 800 \\
$\mathrm{Al} \mathrm{O}_{2} \mathrm{O}$ & $350-380$ & - & 400 (flexural $)$ & - \\
$\mathrm{PS}-\mathrm{ZrO}$ & 200 & - & 800 (flexural $)$ & - \\
Bone (cortical) & $10-20$ & - & $100-300$ & $1-2$ \\
\hline
\end{tabular}

Robert Pillar, Metallic Biomaterials, www.springer.com/.../9780387848716 ${ }^{21}$

Students were then asked to respond to various questions regarding the properties listed in the table based on their knowledge of how atomic bonding affects these properties. As another example, for a homework assignment related to diffusion, students were asked to design a transdermal drug delivery system for a proprietary medication to treat high blood pressure. They were provided the drug concentration, diffusion coefficient, required drug dosage, release material thickness, patch wear time and the amount of drug remaining in the reservoir after this wear time. They were able to design the size and shape of the patch based on this information.

A core learning component of this class was the two mini-projects and the two major projects. Each of these projects was designed to be completed primarily during class time, to be somewhat evenly spaced over the course of a semester and to meet specific course learning objectives. Additionally, these projects were designed to meet specific KEEN learning outcomes. These learning outcomes were that by the end of the semester the students would be able to: define problems, opportunities and solutions in terms of value creation; apply creative thinking to ambiguous problems; demonstrate resourcefulness and collaborate in a team setting. An additional objective for each of these projects was to help students synthesize knowledge gained from various separate chapters in a given unit or over the course of the semester and to relate this 
information in a practical manner to a real world Biomaterial problem. Each of the four assignments embedded multiple ACL techniques such as jigsaw (expert teams) and think-pairshare.

Mini-Project1 - Bonding, Crystal Structure, Slip, Crystallographic Defects and Properties:

The first Mini-Project was designed to occur at the end of the first unit and to serve as a "capstone" assignment to the unit prior to the first test. This mini-project was facilitated during the fourth week of a sixteen week semester. The course specific learning outcome for this miniproject were that by the end of this assignment students would be able to: estimate the general properties of a material based on type of bonding; estimate the general properties of a material based on crystal structure; identify the slip system for common crystal structures; and select the more appropriate material for an application by applying concepts of crystallographic imperfections and slip.

For this activity, students were allowed to self-select their teams of approximately four students each. Students were given three class periods to finish this assignment. Students were presented with the scenario provided below. They were provided with a limited number of materials to choose from and then asked to narrow down their material choice based on their knowledge of the effect of atomic bonding, crystal structure, and crystallographic defects on the properties relevant to this particular application. Students were asked specific questions to help guide their thinking. They were able to use any resource available to them such as their notes, text book, internet, but were strongly encouraged to not try to "find the right answer." Instead, they were asked to apply their general knowledge of atomic bonding and the effect it has on properties as well as their knowledge of crystal structures, crystal defects and slip to solve this problem.

You are part of the engineering team working for the Sable foundation. Your mission is to design low cost prosthetic limbs for victims of national disasters, such as earthquakes. Work done by your foundation is significant and has been featured on news media such as on http://www.pbs.org/newshour/rundown/two-years-later-haitian-amputees-still-have-along-way-to-gol. ${ }^{22}$ Your team is primarily focused on working on the pylon for a transtibial amputee. With the most recent earthquake, you are once again tasked with trying to make improvements on your current design while also understanding the very limited availability of materials in the region you are working. Can you help your team by recommending a material that would be best suited for this application? In thinking about this application, you recall what you know about bone. As a material, bone can be considered a composite that is made up of strong and tough collagen fibers in a mineral matrix of a crystalline calcium phosphate. Long bones such as the tibia and fibula are loaded in both compression and tension (ISO 10328:2006 Prosthetics -- Structural testing of lower-limb prostheses -- Requirements and test methods). 
Mini-Project 2 - Solidification, Diffusion, Phase Diagrams and Heat Treating:

The second Mini-Project was designed to occur at the end of the second unit and to serve as a "capstone" assignment to that unit prior to the second test. This mini-project was facilitated during the tenth week of a sixteen week semester. The course specific learning outcomes for this mini-project were that by the end of the assignment the students would be able to read and interpret a phase diagram and a cooling curve, be able to use a phase diagram to predict the formation of microstructures in a material and to recommend a heat treatment based on desired properties. As with the other mini-project, students were able to self-select their teams of approximately four students each. The students were given two class periods to complete this assignment. Students were presented with the scenario provided below. They were then tasked with "playing" with Nitinol wire and recording their observations. After that they responded to a variety of questions on an accompanying worksheet related to cooling curve, phase diagrams, heat treatment and martensitic transformations.

You are part of the design team for Cordis ${ }^{\circledR}$ that is working on optimizing their selfexpanding vascular stents and also marketing these to medical professionals. These stents are made out of Nitinol which is a Ni-Ti shape memory alloy.

Project 1 - Ethical/Legal Issues, Wound Healing, Corrosion, Testing and Failure Analysis:

The first major project was designed as an inquiry based learning experience. The course specific learning outcomes for this project were that by the end of the assignment the students would be able to identify major forms of corrosion, list the steps associated with a failure analysis, interpret data from a failure analysis, and express an opinion that is backed up with data and facts related to an ethical and legal issue for a biomedical application. Students were able to self-select their teams of four. Students were given four class periods to work on this assignment. For this assignment, students were asked to watch several youtube videos. One of these videos was a news report related to the recall of a hip implant. ${ }^{23,24}$ Embedded in this news report, were personal testimonials as well as information related to lawsuits. Additionally, the students were asked to watch a cosmo learning video of a case study of a failure analysis of a similar hip implant. ${ }^{25}$ Students with information about the modular hip implants and asked to respond to questions related to the types of corrosion identified in the case study, the information obtained at each step of the failure analysis and to identify claims made regarding the physiological response to these implants. Finally, the students were asked to provide a one page opinion paper that discusses the case from one of three viewpoints: the hip implant manufacturer, the patient or the surgeon. They were required to back up their opinion with facts and data.

Project 2- Biomedical Applications, Metals, Polymers, Ceramics and Composites

The second major project was also designed as an inquiry based learning experience. In parallel with this assignment, students were assigned as homework to watch recorded lectures on specific 
material types and then take a five point on-line quiz over the content covered in each of the lectures. The course specific learning outcomes for this project were that by the end of the assignment the students would be able to: translate product design requirements and objectives to specific material properties; use Ashby diagrams as a tool for material selection; use the method of weighted factors as a tool for material selection; access material property data from a variety of reliable web sources, handbooks and text books and properly apply this information for the purpose of material selection and speak knowledgeably about the different material classes. In this project, students were asked to reverse engineer a biomedical device, pick a specific component on this device, research the material that component was currently made from and then use the material selection process to research and select alternative materials for that application. They were required to consider at least one metal, polymer or ceramic. However, if they chose to also research a composite material, that could replace any one of the aforementioned material classes. Student teams were allowed to define their own design objectives for the component. For example, they may have chosen to find an alternative material that would make the component more cost effective, lighter, more "durable," etc. A broad definition of biomedical device was employed to include assistive devices, surgical tools, external fixation devices and implants.

For this project, an attempt was made to form teams based on biomedical application interest. To facilitate this students were asked to individually bring in three ideas of biomedical applications that they were interested in researching. Students then were tasked with talking to at least fifteen different people over a five minute period. Students were asked to form teams of three to five people based on interest. Students were given five class periods to work on this project. At the conclusion of the project, they were asked to share their results through a short five minute presentation. They were challenged to not use a power point presentation, but instead, employ a more creative method to share their information. Nothing was off the table including interpretive dance, theatrical rendition, etc. Extra credit was given for creativity. That being said, a majority of the teams chose power point presentations. Others created videos, or tried to engage the class by asking questions and providing rewards such as candy.

\section{Course and project assessment:}

A variety of methods were used to assess the course as a whole as well as the projects and miniprojects. These methods included Likert scale assessment of the projects, mini-projects and class by the students, comparison of scores on a common final exam between a traditional section of materials with the Biomaterial focused section of materials and comparison of student evaluations of teaching between traditional sections of materials with the Biomaterial focused section of materials taught by the same instructor. It is understood that these methods of assessment are primarily qualitative, but they did provide some meaningful information to the instructor. In particular, the instructor wanted to make sure that the students' learning of key material concepts was not negatively impacted by the additional course content in the Biomaterial focused section of materials. Comparison of the scores on a common final was used 
to determine this. The Likert scale assessments were developed to measure the students' perception of the efficacy of the projects and mini-projects in helping the students understand course concepts, to determine if the students enjoyed the assignments and to seek qualitative feedback so that the assignments could be modified and hopefully improved. For the application project the students were asked to assess the efficacy of that project in meeting specific course related learning outcomes. Additionally, the end of the course assessment was used to determine if the students perceived that they had made gains in developing key elements of an entrepreneurial mindset.

A summary of the responses generated through the Likert scale surveys are provided in Tables 25. For all assessments a five point Likert Scale was used with 5 being Strongly Agree and 1 being Strongly Disagree. Tables 2 and 3 summarize the feedback from the mini-projects and projects. For the assessments summarized in Tables 2 and 3, the averaged Likert scale scores ranges from 3.89 to 4.42 which is in the "agree" to "strongly agree" range. As can be seen from Tables 2 and 3, the students felt that the mini-projects and projects were a fun way to review and helped them to better understand the course content and achieve the learning outcomes.

Additionally, the students felt that they had sufficient time to work on these activities and that the worksheets helped to guide them to a solution.

Table 4 shows student feedback on the Biomaterial Focused course as a whole. For this assessment, the average Likert scale scores ranged from 3.10 to 4.60 which is in the "neutral" to "strongly agree" range. As can be seen from this table, students did not necessarily sign up for this course because of the Biomaterial focus. Although, the Biomaterial focus of this section of the course was advertised at registration, some students chose this section due to the instructor or scheduling. Despite this, the students felt that the applications and projects were helpful to their learning and made them more interested in material. In the open response question, one student commented, "I have never had an interest or class with Biomaterials, so it was interesting but not what I am interested in." Another student commented, "The projects allowed us to see how the concepts we were learning applied to actual Biomaterial applications."

Table 2. Assessment of Mini-Projects 1 and 2 and Project 1.

\begin{tabular}{|c|c|c|c|} 
& Mini-Proj 1 & Mini-Proj 2 & Proj 1 \\
\cline { 2 - 4 } & Prosthetic Limb & Nitinol Stent & Failure Analysis \\
\hline This activity was a fun way to review & 4.11 & 4.35 & 4.31 \\
\hline $\begin{array}{c}\text { This activity helped me to better understand the } \\
\text { concepts in this unit }\end{array}$ & 4.32 & 4.32 & 4.12 \\
\hline I had sufficient time to complete this activity & 3.89 & 4.26 & 4.42 \\
\hline $\begin{array}{c}\text { The worksheet helped guide us through the } \\
\text { problems. }\end{array}$ & 4.26 & 4.39 & 4.35 \\
\hline \begin{tabular}{c} 
Tyyy \\
\hline
\end{tabular}
\end{tabular}


Table 3. Assessment of Project 2-Biomedical Application Material Selection

\begin{tabular}{|l|c|} 
& Total \\
\hline $\begin{array}{l}\text { This activity helped me to understand how to translate product } \\
\text { design requirements and objectives to specific material properties. }\end{array}$ & $\mathbf{4 . 4 5}$ \\
\hline $\begin{array}{l}\text { This activity exposed me to the use of Ashby diagrams as a tool for } \\
\text { material selection. }\end{array}$ & $\mathbf{4 . 2 0}$ \\
\hline This activity helped me learn how to access material data. & $\mathbf{4 . 2 0}$ \\
\hline $\begin{array}{l}\text { This activity helped me to gain a better understanding of material } \\
\text { properties, in particular speak knowledgeably about the different } \\
\text { material classes. }\end{array}$ & $\mathbf{4 . 4 5}$ \\
\hline $\begin{array}{l}\text { This activity helped me to better understand the process of } \\
\text { selecting a material for an application. }\end{array}$ & $\mathbf{4 . 5 5}$ \\
\hline $\begin{array}{l}\text { I had sufficient time in class to complete this activity. } \\
\text { The worksheet helped guide us through the material selection } \\
\text { process. }\end{array}$ & $\mathbf{4 . 1 5}$ \\
\hline
\end{tabular}

Table 4. Student Feedback on Biomaterial Focused Section of Materials

\begin{tabular}{|l|c|}
\hline Course Evaluation & Total \\
\hline $\begin{array}{l}\text { I chose this section of materials because of the } \\
\text { biomaterial focus. }\end{array}$ & 3.10 \\
\hline $\begin{array}{l}\text { I chose this section of materials because of the time it } \\
\text { was offered. }\end{array}$ & 4.25 \\
\hline $\begin{array}{l}\text { I chose this section of materials because of the } \\
\text { instructor. }\end{array}$ & 4.60 \\
\hline $\begin{array}{l}\text { I found the biomaterial applications and activities to } \\
\text { be helpful in increasing my interest in the topic of } \\
\text { materials. }\end{array}$ & 3.95 \\
\hline $\begin{array}{l}\text { I found the biomaterial applications and activities to } \\
\text { be helpful to my learning. }\end{array}$ & 4.10 \\
\hline
\end{tabular}

At the end of the semester, the KEEN Fellow Program evaluator asked each of the KEEN Fellows to assess the efficacy of their courses at meeting some of the KEEN learning outcomes related to the entrepreneurial mindset as defined by KEEN. ${ }^{4}$ The students were asked to respond to the questions provided in Table 5 regarding their perception of the efficacy of the Biomaterial Focused Material course in helping them develop some of the key components associated with an entrepreneurial mindset. For this assessment the average Likert Scale scores ranged from 3.31 to 4.38 which is in the "neutral" to "agree" range. Data from Table 5 suggests that the Biomaterial Focus course was most effective in the area of making Connections and Entrepreneurship and least effective in the area of Creating Value. Overall, however, the data 
suggest that his course was effective in helping the students develop all of the components associated with the entrepreneurial mindset. Because this assessment was not available at the beginning of the semester, it was not possible to facilitate it as a pre/post survey. This is unfortunate as it would have been interesting to assess the students' perception of their abilities in these key attributes of an entrepreneurial mindset at the beginning of the semester to see if there was any growth in these areas as a result of their participation in the Biomaterial focused section of this course. Furthermore, it would have been advantageous to compare this information to a control group of students enrolled in a regular section of Materials course taught by the same instructor. This was not possible, since the instructor taught only one section of the course that semester.

Table 5. Student Self-Assessment of the Efficacy of Biomaterial Focus Course at Meeting the KEEN Learning Outcomes Related to the Entrepreneurial Mindset

\begin{tabular}{|c|c|}
\hline Entrepreneurial Mindset and KEEN Learning Outcomes & Total \\
\hline Developing Curiosity as indicated by: & \\
\hline I asked questions beyond that of the original course question. & 3.31 \\
\hline I used additional methods for finding answers to questions/problems and I identified & 3.44 \\
\hline I identified alternative applications, choices or solutions through the projects/problems. & 3.81 \\
\hline Making Connections as identified by: & \\
\hline I used information from multiple sources to generate a solution to a project/problem. (e.g., & $\mathbf{4 . 3 8}$ \\
\hline I addressed multiple facets of the project (multiple constraints and objectives). & 3.81 \\
\hline I addressed the risks and contingencies in my solutions. & 3.44 \\
\hline Creating Value as identified by: & \\
\hline I explored unexpected opportunities/value (e.g., research gap, originality and significance, & $\mathbf{3 . 1 3}$ \\
\hline I discussed or identified novel, unique, unexpected approaches/conclusions/solutions. & $\mathbf{3 . 1 9}$ \\
\hline I considered cost-saving possibilities. & $\mathbf{3 . 5 3}$ \\
\hline I developed an action plan. & $\mathbf{3 . 3 1}$ \\
\hline I designed or considered a method to demonstrate improvement/success (e.g., preliminary & $\mathbf{3 . 1 3}$ \\
\hline Entrepreneurship in general as identified through: & \\
\hline Effective presentation/explanation & $\mathbf{3 . 9 4}$ \\
\hline Appropriate use of vocabulary/terminology & $\mathbf{3 . 8 1}$ \\
\hline
\end{tabular}

In an effort to compare longitudinal trends with regards to student learning in Materials, the instructor of this course has facilitated a common 150 point cumulative final for the past several years. The format of this final is 75 multiple choice questions. The final is not returned to the students. They only receive their scores. Table 6 shows the scores of these finals for three different course structures. In the spring of 2014, the instructor employed ACL and PBL, but not EML pedagogies in two sections of the course. In two sections of the course for both the fall of 2014 and spring of 2015 semesters, the course was modified to include EML projects and assignments, but did not have the Biomaterial focus. In the fall of 2015, the Biomaterial focus section of the class was offered to one section of materials. All of these sections of the course 
were facilitated by the same instructor. As can be seen from Table 6, no significant difference was noted in the common final exam scores from the spring of 2014 through the fall of 2015. This data suggests that the extra course content facilitated in the Biomaterial Focus section of the materials course did not negatively impact the students' learning of fundamental material concepts.

Table 6. Comparison of Scores on a Common 150 Point Final for Materials Course Facilitated by Same Instructor but Employing Different Pedagogy

\begin{tabular}{|l|c|c|c|c|}
\multicolumn{1}{|c|}{ Semester } & $\mathbf{n}$ & Mean & St. Dev & Median \\
\hline $\begin{array}{l}\text { Spring 2014 (did not EML } \\
\text { Assignments, but did use ACL } \\
\text { and PBL) }\end{array}$ & 78 & 120.47 & 10.11 & 120.00 \\
\hline $\begin{array}{l}\text { Fall 2014 (incorporated } \\
\text { EML, ACL and PBL) }\end{array}$ & 82 & 115.90 & 15.35 & 117.00 \\
\hline $\begin{array}{l}\text { Spring 2015 (incorporated } \\
\text { EML, ACL and PBL) }\end{array}$ & 76 & 119.74 & 13.97 & 123.00 \\
\hline $\begin{array}{l}\text { Fall 2015 (Biomaterial Focus } \\
\text { with EML, ACL and PBL) }\end{array}$ & 35 & 117.83 & 15.78 & 118.00 \\
\hline
\end{tabular}

Often times, engineering faculty members are hesitant to employ innovative pedagogies for fear that these techniques will have a negative impact on their teaching evaluations. In an effort to determine if the Biomaterial focus section had a negative impact on the teaching evaluations, the Student Evaluation of Teaching (SET) results were compared for the same instructor for the regular sections of Materials offered during the spring of 2015, with the Biomaterial Focused section offered during the fall of 2015, Table 7. ACL, PBL and EML were employed for all of these sections. It would also have been very useful to compare the SET for a semester where EML was not employed. Unfortunately, however, the university changed the evaluation forms, questions and method used to facilitate these forms after the fall of 2014. As such, comparing the SET from any semester prior to the spring of 2015 would not have been a valid assessment. As can be seen from Table 7, the SET results were not negatively impacted in the Biomaterial Focused section. In fact, for some of the questions such as "I learned a great deal from this course" and "I would recommend this course to other students," there were slight gains in the scores for the Biomaterial Focus section. 
Table 7. Comparison of Regular Materials Course with the Biomaterial Focused Section's Student Evaluation of Teaching for the Same Instructor

\begin{tabular}{|c|c|c|c|c|c|c|c|c|c|}
\hline \multirow{3}{*}{ Student Evaluation of Teaching } & \multicolumn{6}{|c|}{ Materials Course with ACL/PBL - No Biomaterial Focus } & \multirow{2}{*}{\multicolumn{3}{|c|}{\begin{tabular}{|c|} 
Materials Course- Biomaterial Focus \\
Fall 2015 Sect 1 \\
\end{tabular}}} \\
\hline & \multicolumn{3}{|c|}{ Spring 2015 Sect 1} & \multicolumn{3}{|c|}{ Spring 2015 Sect 3} & & & \\
\hline & $\mathrm{n}$ & Avg & StDev & $\mathrm{n}$ & Avg & StDev & $\mathrm{n}$ & Avg & StDev \\
\hline The instructor seemed organized. & 19 & 4.7 & 0.55 & 19 & 4.4 & 0.81 & 16 & 4.5 & 0.61 \\
\hline I knew what I was expected to accomplish in this course. & 19 & 4.6 & 0.48 & 19 & 4.3 & 0.85 & 16 & 4.4 & 0.61 \\
\hline The instructor presented the subject matter clearly. & 19 & 4.6 & 0.49 & 19 & 4.4 & 0.75 & 16 & 4.5 & 0.61 \\
\hline $\begin{array}{l}\text { The instructor created an environment that supported my } \\
\text { learning. }\end{array}$ & 19 & 4.7 & 0.44 & 19 & 4.5 & 0.94 & 16 & 4.9 & 0.24 \\
\hline The instructor demonstrated a genuine interest in my success. & 19 & 4.5 & 0.94 & 19 & 4.5 & 0.75 & 16 & 4.9 & 0.33 \\
\hline $\begin{array}{l}\text { The feedback I received from the instructor improved my } \\
\text { learning. }\end{array}$ & 19 & 4.2 & 1.04 & 19 & 4.4 & 0.67 & 16 & 4.8 & 0.39 \\
\hline This course stimulated my interest in the subject. & 19 & 4.2 & 1.09 & 19 & 4.3 & 0.64 & 16 & 4.4 & 0.79 \\
\hline This course increased my understanding of the subject. & 19 & 4.5 & 0.94 & 19 & 4.5 & 0.60 & 16 & 4.5 & 0.61 \\
\hline I learned a great deal from this course & 19 & 4.5 & 0.68 & 19 & 4.4 & 0.67 & 16 & 4.6 & 0.61 \\
\hline I would recommend this course to other students & 19 & 4.2 & 1.00 & 19 & 4.3 & 0.80 & 16 & 4.8 & 0.39 \\
\hline I would recommend this instructor to other students & 19 & 4.6 & 0.94 & 19 & 4.6 & 0.75 & 16 & 4.9 & 0.24 \\
\hline
\end{tabular}

\section{Summary of Findings:}

One of three sections offered in the fall of 2015 of a junior level Introduction to Materials course was modified to have a Biomaterial focus and to employ ACL, PBL and EML assignments and projects aimed at fostering the entrepreneurial mindset in the students. Seven homework assignments, two mini-projects and two major projects were created or adapted to include biomedical applications of materials and material science concepts. Various methods were used to assess the Biomaterial focused section of the materials course. These methods included Likert scale assessment of the projects, mini-projects and class by the students, comparison of scores on a common final exam between traditional sections of materials with the Biomaterial focused section of materials and comparison of student evaluations of teaching between traditional sections of materials with the Biomaterial focused section of materials taught by the same instructor. Results of these assessments suggest that the students enjoyed the projects and miniprojects and found them helpful to their learning of the course content. Furthermore, the students felt that the course helped them develop their entrepreneurial mindset by fostering creativity, allowing them to make connections and to think about the relevance of the course content to creating value. Despite the additional content that was added to the Biomaterial Focused section of the materials course, scores from a common final exam suggest that the students in the Biomaterial focused section had the same level of achievement as those in the regular sections of materials. Although some of the students did not sign up for this course because of the Biomaterial focus, most of the students felt that the Biomaterial applications and projects were helpful to their learning and made them more interested in the course content. The instructor's teaching evaluations were not negatively impacted when this instructor facilitated the Biomaterial Focus section of materials. Based on these results, it can be concluded that offering 
a thematic section of a course can be a good way to get students interested in the course content, to bring in projects that have a common theme and to help develop the students' entrepreneurial mindset. Slight modification of the course, including developing thematic homework and projects and adjusting the schedule to accommodate additional content are required, but can provide benefits to the students as well as the instructor.

\section{Bibliography}

1. Kern Foundation, http://www.kffdn.org/files/keenzine-2-framework.pdf, accessed January 22, 2015.

2. Fry, C.,et. al., "AC 2010-2218: Bringing Innovation and the Entrepreneurial Mindset (back) into Engineering: the KEEN Innovators Program, Proceedings of the ASEE 2010 Annual Conference and Exposition,” ASEE, 2010.

3. Fry, C., et. al., "Working Collaboratively Among Universities: A Dense Network Approach," Proceedings of the 2012 ASEE Annual Conference and Exposition, ASEE 2012.

4. KEEN Network, http://www.keennetwork.org, accessed January 22, 2015.

5. Carpenter, D., Gerhart, A., "PBL, ACL and Entrepreneurial Minded Learning Workshop," University of Dayton, Jan 17, 2016.

6. Carpenter, D., Feierfeil, G., "Cultivating an Entrepreneurial Mindset Through Interdisciplinary Collaboration and Networking," Proceedings of the 2007 American Society of Engineering Education Annual Conference and Exposition, ASEE, 2007.

7. Jonassen, D.H., Khanna, S.K., "Implementing Problem Based Learning in a Materials Science Course,'Proceedings of the 2011 ASEE Annual Conference and Exposition, ASEE, 2011.

8. Malicky, D., Huang, M., Lord, S.," Problem, Project, Inquiry or Subject Based Pedagogies: What to Do?”, Proceedings of the 2006 ASEE Annual Conference and Exposition, ASEE 2006.

9. Jayaram, S., "Implementation of Active Cooperative Learning and Problem-Based Learning in an Undergraduate Control Systems Course," Proceedings of the 120 th ASEE Annual Conference and Exposition, ASEE, 2013.

10. Frank,M, Lavy,I., Elata, D., "Implementing the Project-Based Learning Approach in an Academic Engineering Course," International Journal of Technology and Design Education: 13, (2003): 373-288.

11. Petersen, O., Jordan, W., Radharamanan, R., “AC 2012-3655: Proposed Keen Initiative Framework For Entrepreneurial Mindedness in Engineering Education," Proceedings of the 2012 ASEE Annual Conference and Exposition, ASEE, 2012.

12. Thoroughman, K., Hruschka, A., Widder, P., "Engineering Virtual Studio: KEEN Modules to Foster Entrepreneurial Mindset in an Integrative, First/Second Year Online Course," Proceedings of the 2014 ASEE Annual Conference and Exposition, ASEE, 2014.

13. Milton, D., Bridging the Knowledge Gap, KEEN'zine Issue 2, accessed Jan 22, 2015.

14. Bloom, B.S. (Ed.). Engelhart, M.D., Furst, E.J., Hill, W.H., Krathwohl, D.R., Taxonomy of Educational Objectives, Handbook I: The Cognitive Domain. New York: David McKay Co Inc, 1956.

15. Visioneering Center, https://www.udayton.edu/news/articles/2014/12/visioneering center.php, accessed Dec 29, 2015.

16. University of Dayton Catalog, http://catalog.udayton.edu/allcourses/bie/ , accessed Jan. 13, 2016.

17. US Bureau of Labor Statistics http://www.bls.gov/ooh/architecture-and-engineering/biomedical-engineers.htm, accessed Jan 18, 2016.

18. ASEE Report, https://www.asee.org/papers-and-publications/publications/14_11-47.p, accessed Jan. $10,2016$.

19. Pinnell, M., Gunasekaren, S. Berkemeier, G., "Project Based Learning in an Introduction to Materials Course," Proceedings of the 2015 ASEE North Central Section Conference, ASEE 2015.

20. Hip Implants, http://www.camdonfary.com.au, accessed July 15, 2015. 
21. Pillar, R., Metallic Biomaterials, www.Springer.com, accessed June 30, 2015.

22. PBS, http://www.pbs.org/newshour/rundown/two-years-later-haitian-amputees-still-have-a-long-way-to-go/, accessed May 2013.

23. WNEM, http://www.wnem.com/story/27471970/faulty-hip-replacement-recall-reaches-settlement, accessed May $5,2013$.

24. https://www.youtube.com/watch?v=LqBpBQIok94, accessed July 13, 2015.

25. CosmoLearning, http://cosmolearning.org/video-lectures/case-study-hip-implant-corrosion/, accessed June 9, 2014. 